\title{
Indo-Pacific Phylogeography of the Lemon Sponge Leucetta chagosensis
}

\author{
Olivier Pasnin ${ }^{1,2, *}$, Oliver Voigt ${ }^{3}$, Gert Wörheide ${ }^{3,4,5}$, Andrea P. Murillo Rincón ${ }^{3}$ \\ and Sophie von der Heyden ${ }^{1}$ (D) \\ 1 Department of Botany \& Zoology, University of Stellenbosch, Private Bag X1, Matieland 7602, South Africa; \\ svdh@sun.ac.za \\ 2 Mauritius Oceanography Institute, Avenue des Anchois, Morcellement de Chazal, Albion 91005, Mauritius \\ 3 Department of Earth and Environmental Sciences, Palaeontology and Geobiology, \\ Ludwig-Maximilians Universität München, Richard-Wagner-Str. 10, 80333 München, Germany; \\ oliver.voigt@lmu.de (O.V.); woerheide@lmu.de (G.W.); amurillo@zoologie.uni-kiel.de (A.P.M.R.) \\ 4 GeoBio-Center, Ludwig-Maximilians-Universität München, Richard-Wagner-Str. 10, \\ 80333 München, Germany \\ 5 SNSB- Bayerische Staatssammlung für Paläontologie und Geologie, Richard-Wagner-Str. 10, \\ 80333 München, Germany \\ * Correspondence: opasnin@moi.intnet.mu
}

Received: 10 October 2020; Accepted: 27 November 2020; Published: 7 December 2020

check for updates

\begin{abstract}
The sponge Leucetta chagosensis Dendy (1913) has a wide distribution throughout the Indo-Pacific (IP) region, with previous studies focussing primarily on the western Pacific Ocean. To increase our knowledge of the spatial variation of genetic diversity throughout the IP, we constructed a phylogeny for L. chagosensis for the IP to assess the evolutionary patterns for this species. We generated 188 sequences of $L$. chagosensis and constructed maximum likelihood and Bayesian inference trees, using concatenated mitochondrial cytochrome oxidase subunit 3 gene (cox3) and nuclear ribosomal RNA gene (28S) markers for the first time. The spatial variation of genetic diversity of L. chagosensis was assessed using a phylogeographic approach. Leucetta chagosensis is composed of five cryptic lineages confined to different biogeographic regions with the specimens found in the Indian Ocean differing significantly from those found in the rest of the IP region. Genetic divergence was particularly high for the cox 3 marker, with a low nucleotide diversity but high haplotype diversity for most lineages. This study highlights the need for a sustained effort in studying sponge diversity, boosted by the ongoing discovery of hidden biodiversity among this ecologically important taxon.
\end{abstract}

Keywords: cryptic lineages; marine diversity; Indian Ocean; marine species evolution

\section{Introduction}

Phylogeography has provided numerous insights into the distribution of genetic variation in terrestrial and aquatic ecosystems. In particular, it has contributed to our understanding of the evolutionary history and spatio-temporal genetic divergence of species, with broad implications ranging from systematics and taxonomy [1,2] to conservation [3,4]. In addition, phylogeographical studies have the potential to support effective conservation strategies [5], especially for threatened marine environments like the Indian Ocean [6,7].

The Indian Ocean (IO), is recognised as one of the world's marine biodiversity hotspots, with a high number of endemic species [8-10]. The IO has been neglected from a bio- and phylogeographical standpoint, particularly compared to the rest of the Indo-Pacific (IP) region [11]. This lack of information is particularly concerning because baseline biodiversity information is essential for any conservation plan that aims to mitigate climate change impacts [12-15] and over-exploitation [16-18]. Recent studies have 
emphasised a biogeographic break between reef species of the Indian and Pacific Oceans. For example, distinct genetic lineages have been observed between reef fish species [19,20] and coral reef sea stars [21-23] of the Indian and Pacific Oceans, respectively. Such genetic discontinuities are important from a conservation perspective, as populations of marine species in these regions likely experience unique evolutionary dynamics, which require separate management and conservation prioritisation.

Sponges are important functional components of reef ecosystems in the IP region [24,25], but few studies have focussed on their diversity and phylogeography so far-a gap we aim to close with this study. We chose the calcareous "lemon" sponge Leucetta chagosensis (Order: Clathrinida, Family: Leucettidae) as the target species of this study for several reasons.

First of all, the lemon sponge has a wide distribution, ranging from the Red Sea and the Coral triangle region to the central Pacific, thus covering the whole Indo-Pacific region. Leucetta chagosensis was first described by Dendy (1913) [26] from the IO Chagos Archipelago. The sponge was later reported in different areas in the IP, as well as other places in the IO (Figure 1). Recently, L. chagosensis has been observed in Rodrigues Island [25] and Reunion Island [27], although it has not yet been detected in Mauritius (Pasnin, pers. Comm.) (Figure 1).

Second, compared to other calcareous sponges, L. chagosensis is abundant and can be easily identified because of its bright lemon-yellow colour. It is usually found in shaded areas [28] at depths below $15 \mathrm{~m}$ [29], and the species can locally be relatively abundant compared to other sponges. Like all calcareous sponges [30], it is viviparous, and therefore assumed to have limited dispersal capabilities [28].

Third, the species has been subject to previous phylogeographic studies, which have focussed (although not exclusively) on the Pacific region [28,29]. In these studies, deeply diverged clades were discovered: two large and sub structured overlapping clades in the north west (NW) and south west (SW) Pacific, with a geographical overlap in the Great Barrier Reef and the Coral Sea. The other divergent clades were observed from individuals sampled from the Maldives and the Red Sea, forming a distinct clade, and also another clade grouping individuals found in the Philippines [29]. The overlapping distribution of genetically divergent clades [28,29] suggests that reproductive barriers exist between them, supporting the hypothesis of ongoing speciation processes within L. chagosensis. Samples from the Southern IO were not included. Still, they may be crucial for understanding the phylogeography of the species-for example, like in the Acanthaster planci-species complex [22,31], in which deep genetic breaks exists between Northern and Southern IO. Additionally, both previous studies on L. chagosensis phylogeography [28,29] were based entirely on nuclear loci, because mitochondrial markers were not available at that time, due to the markedly different organization of the mitochondrial genomes of calcareous sponges compared to other metazoans [32]. Including mitochondrial markers has been proven to improve the resolution of relationships between geographic regions, also among sponge species [33-35]. Most sponges have low mitochondrial variation [36] compared to other marine species. However, the first unambiguously identified mitochondrial genes from calcareous sponges exhibited an unusually high genetic variation, exceeding the one characterizing other sponges [32,37]. A pilot study by Voigt et al. [37] with L. chagosensis demonstrated the high-resolution potential of the mitochondrial gene of cytochrome oxidase subunit 3 (cox3) by analysing samples of the target species from its NW and SW Pacific clades. Only one sample from the IO (Red Sea) was included in that study.

Here, for the first time, we comprehensively analyse the phylogeographic structure of L. chagosensis over its distribution range with both nuclear and mitochondrial markers. In this way, we were able to widen our sample size and improve the resolution power of our analyses. The aims of this study were to (1) assess if the L. chagosensis found in the central IO is isolated from the Pacific Ocean (PO) and (2) unravel the evolutionary relationships of L. chagosensis. We hypothesise that, given the viviparous life history trait of $L$. chagosensis, limits to long-distance dispersal do probably exist. As a consequence, the alleged wide geographic distribution of the species throughout the IP could be an overestimation. In particular, we hypothesise that L. chagosensis found in the central IO has diverged from those found in the PO and that the nominal L. chagosensis is composed of different cryptic lineages that are evolving separately in their specific biogeographic regions. 


\section{Materials and Methods}

\subsection{Sequence Generation}

For this study, we generated 162 cox3 and $5628 S$ new sequences of L. chagosensis collected from Indian Ocean, as well the western and central Pacific Oceans, except for the Taiwan region (Table 1). In addition, we included 35 and 146 available mtDNA partial cytochrome oxidase subunit III gene cox3 and $28 S$ sequences, respectively [28,29,37]. The compiled dataset of 209 L. chagosensis samples covers its entire range, encompassing sites in the Indian and Pacific Oceans (Table 1), making this the most comprehensive dataset available to date. Detailed information of the specimens and their sequences is provided in Supplemental S1.

Table 1. Number of specimens included in the analyses.

\begin{tabular}{|c|c|}
\hline Sampling Region & Number of Specimens \\
\hline \multicolumn{2}{|c|}{ Indian Ocean } \\
\hline Rodrigues & 25 \\
\hline Red Sea & 7 \\
\hline Maldives & 9 \\
\hline \multicolumn{2}{|c|}{ Western Pacific Ocean } \\
\hline Australia & 90 \\
\hline Guam & 4 \\
\hline Indonesia & 14 \\
\hline Papua New Guinea & 19 \\
\hline Palau & 2 \\
\hline Taiwan & 2 \\
\hline Japan & 4 \\
\hline Philippines & 10 \\
\hline \multicolumn{2}{|c|}{ Central Pacific Ocean } \\
\hline American Samoa & 5 \\
\hline Fiji & 2 \\
\hline Polynesia & 8 \\
\hline Vanuatu & 8 \\
\hline
\end{tabular}

The DNA of newly collected specimens was extracted using the NucleoSpin Tissue kit (Machery-Nagel) following the manufacturer's instructions. DNA extracts from other specimens were available from previous studies [28,29]. PCR amplification followed Voigt et al. [37] for the mtDNA partial cytochrome oxidase subunit III gene (cox3) and Wörheide et al. [28] for nuclear 285 markers. All PCR products were run on a 1\% agarose gel (BioWhittaker Molecular Applications) and gel-purified using Biospin Gel Extraction Kits, following the manufacturer's instructions. All products were sequenced on an ABI 3730 Capillary sequencer with Big Dye terminator chemistry (Applied Biosystems) at the Central Analytical Facility at Stellenbosch University or at the Biozentrum of the Ludwig-Maximilians-Universität Munich. Forward and reverse sequences were aligned in CodonCode Aligner (https://www.codoncode.com/) or Geneious v11.1.5 (http://www.geneious.com; [38]). Generated sequences were submitted to GenBank (http://www.ncbi.nlm.nih.gov) and the European Nucleotide Archive (http://www.ebi.ac.uk/ena) and are available under the accession numbers provided in Supplemental S1.

\subsection{Phylogenetic Reconstructions}

Of the 209 specimens, both markers, cox3 and 28S, were available for 188 individuals (Supplemental S1). These 188 sequences of each marker were aligned using Muscle 3.8.425 [39] implemented in Geneious, with default parameters and manually trimmed to same lengths. The resulting sequence lengths for the cox3 and $28 \mathrm{~S}$ alignments were $412 \mathrm{bp}$ and $306 \mathrm{bp}$, respectively. Every sequence was checked for poriferan origin (specifically L. chagosensis) against the NCBI database before downstream analyses, in order to validate the morphological taxonomy. The cox3 sequences were checked for their reading frame by translating them with the reported calcinean-specific mitochondrial genetic code [32]. The two gene fragments were concatenated, but divided into two partitions, protein-coding (cox3) and non-protein-coding (28S), 
before finding for the best partition scheme and nucleotide evolutionary model using ModelFinder in IQ-Tree $[40,41]$ under the Bayesian information criterion (BIC). The best partition scheme and model used for the concatenated sequences are found in Supplemental S2. Attempts to include the closely related species Pericharax orientalis as an outgroup were omitted because no robust positioning of the root was possible. For $28 S$, the genetic variation was too low to find a reasonably supported root position, while for the mitochondrial cox3 marker, the previously documented, extraordinarily high variation in mitochondrial protein-coding genes in Calcinea [32] produced a very long branch to the outgroup. Even at the amino-acid level, the p-distance between P. orientalis and L. chagosensis was about $40 \%$. An appropriate outgroup is required for L. chagosensis, as for now it is difficult to find a suitable one due to the high divergence of the cox3 marker with L. chagosensis [37]. Moreover, there is no molecular clock available for the class Calcarea. For these reasons, all trees were midpoint rooted.

Maximum likelihood (ML) and Bayesian inference (BI) midpoint rooted trees were constructed respectively using IQ-Tree [42], with 2000 ultrafast-bootstrap replicates and MrBayes [43,44], with a chain length (three heated and one cold chain) of 10,000,000 generations and discarding the first $25 \%$ of trees as burn-in. Single marker trees were reconstructed for each partition first, and then subsequently with the concatenated dataset to assess any difference in the topology obtained. The ultrafast bootstrap values for the ML tree were obtained with single branch tests (SH-like approximate likelihood ratio test) implemented in IQ-Tree. The parameters for the Bayesian trees were checked using the trace output, and convergence was accepted when values for an average standard deviation for split frequencies were well below 0.01 and effective sample size values were above 200 . All trees were visualised and formatted using Figtree v1.4.4 (tree.bio.ed.ac.uk/software/figtree/). Sequences with identical haplotypes forming a monophylum were collapsed for each biogeographic region sampled.

\subsection{Population Structure and Genetic Diversity}

To assess the relationships among haplotypes, TCS networks of all cox3 and 285 sequences were constructed separately in Popart 1.7 [45]. DNAsp v6 [46] was used to calculate the number of haplotypes per sampling region. Also, haplotype and nucleotide diversities were calculated for the different biogeographic groupings shown in Figures 1 and 2. An AMOVA was conducted in Arlequin 3.5 [47], with five groups following the different clades observed in the haplotype network and phylogenetic tree, in order to assess the level of genetic differentiation within and between the groupings obtained.

\section{Results}

\subsection{Phylogenetic Reconstruction}

The separate ML (Supplementals S3 and S4) and BI-based phylogenetic reconstructions for the cox3 and $28 S$ markers were different, with the phylogeny estimated from cox3 having higher support based on bootstrap and posterior probability values. One main difference was that in the 28S-based phylogeny, the samples from the Philippines were not reciprocally monophyletic, whereas they were in the cox3-based phylogeny, where they formed a separate clade (Supplemental S3). The ML and BI tree from the concatenated sequences were congruent (Supplemental S5 \& Figure 1), and here the samples from the Philippines formed a reciprocally monophyletic group. The concatenated tree provided evidence for five clades, with most lineages having high support values (Figure 1). Clade 1 (green in Figure 1) contained most of the samples from the western Pacific, grouping specimens from Australia, Papua New Guinea, Vanuatu, Fiji, American Samoa, and Polynesia. Clade 2 (purple in Figure 1) included specimens from the IO only, with samples collected from the Red Sea, Maldives, and Rodrigues. Clade 3 (orange in Figure 1) grouped some of the samples from the Australian coast (orange in Figure 1), found around the Great Barrier Reef region, and also samples from Papua New Guinea, Palau, Guam, and Taiwan (orange in Figure 1). Clade 4 (blue in Figure 1) was comprised of samples collected in Indonesia and Japan, but grouped no samples from areas in between (for instance, Taiwan and the Philippines). Clade 5 (turquoise in Figure 1) was comprised of only samples from the Philippines. 


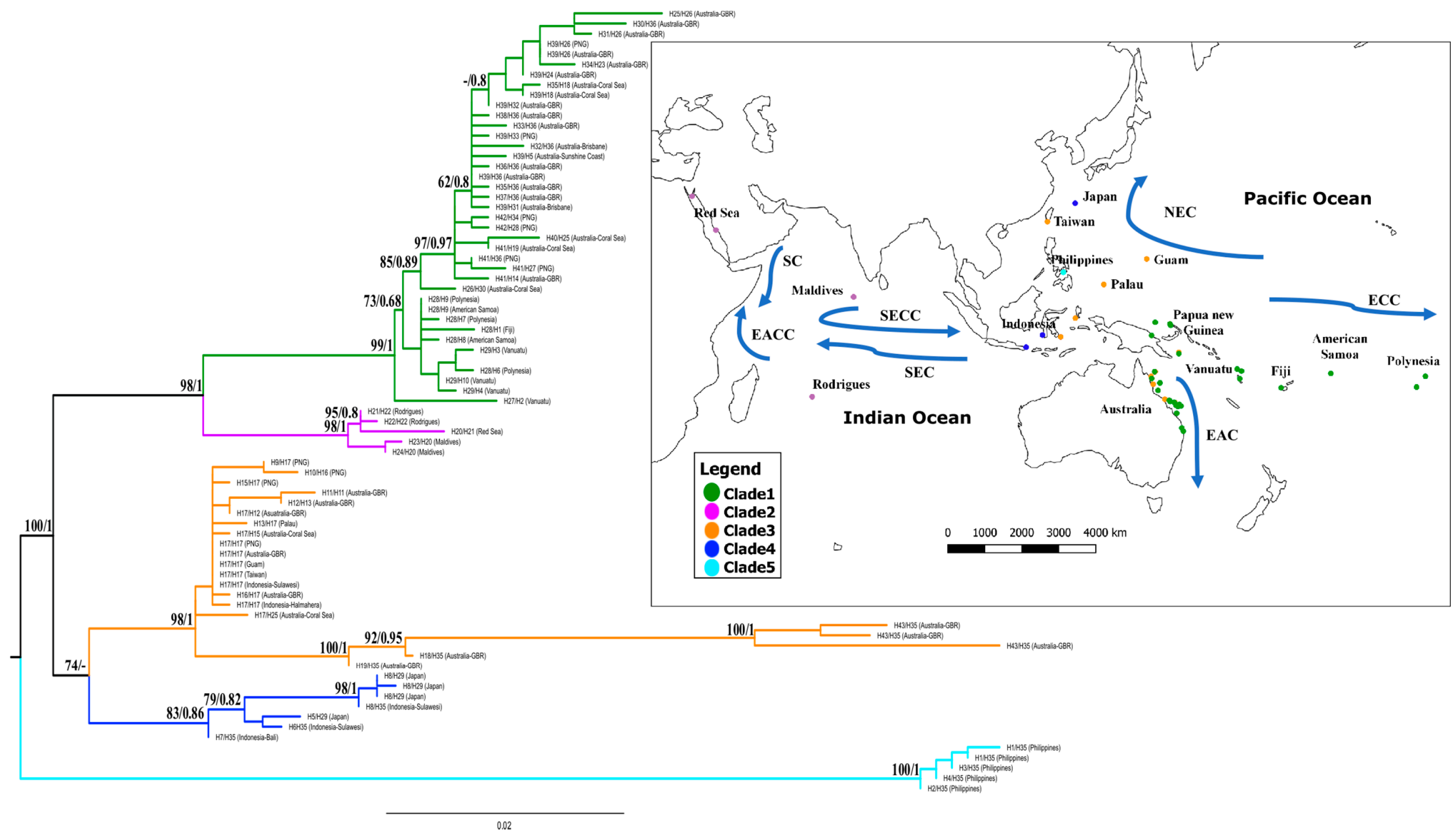

Figure 1. Midpoint rooted ML phylogenetic tree with concatenated sequences of cox3 and 28S, and a map of the sampling localities. Collapsed haplotypes for each gene (cox3/28S), with localities shown on root tips (refer to Supplemental S1). Ultrafast bootstrap values (UBV) above 60 and posterior probabilities (PP) above 0.60 are shown (UBV/PP). Main currents: SC = Somali current, EACC = East African coastal current, SECC = South Equatorial counter current, $\mathrm{SEC}=$ South Equatorial current, $\mathrm{NEC}=$ North Equatorial current, $\mathrm{ECC}=$ Equatorial counter current and EAC $=$ East Australian current. 


\subsection{Population Structure and Genetic Diversity}

The haplotype network based on cox3 sequences (Figure 2) generated more information in terms of haplotype diversity than the one obtained from 285 sequences (Supplemental S6). The relationship between the 45 haplotypes is described in the cox3 haplotype network (Figure 2), with the main groupings corresponding to the five clades obtained from the phylogenetic tree (Figure 1). The number of haplotypes obtained from cox 3 and $28 S$ for each study region, with their respective clades obtained from the phylogenetic tree, is provided in Supplemental S7. Clades 1 \& 3 grouped haplotypes from different geographic locations, namely Australia and Papua New Guinea. Moreover, haplotypes from Australia showed strong differentiation separated by 20 mutational steps in Clade 3 . The haplotypes from Rodrigues, the Red Sea and the Maldives were grouped in Clade 3, but were all separated according to their geographic location. The most distinct haplogroup contained the haplotypes from the Philippines (Clade 5 in Figures 1 and 2), separated by 35 mutational steps.

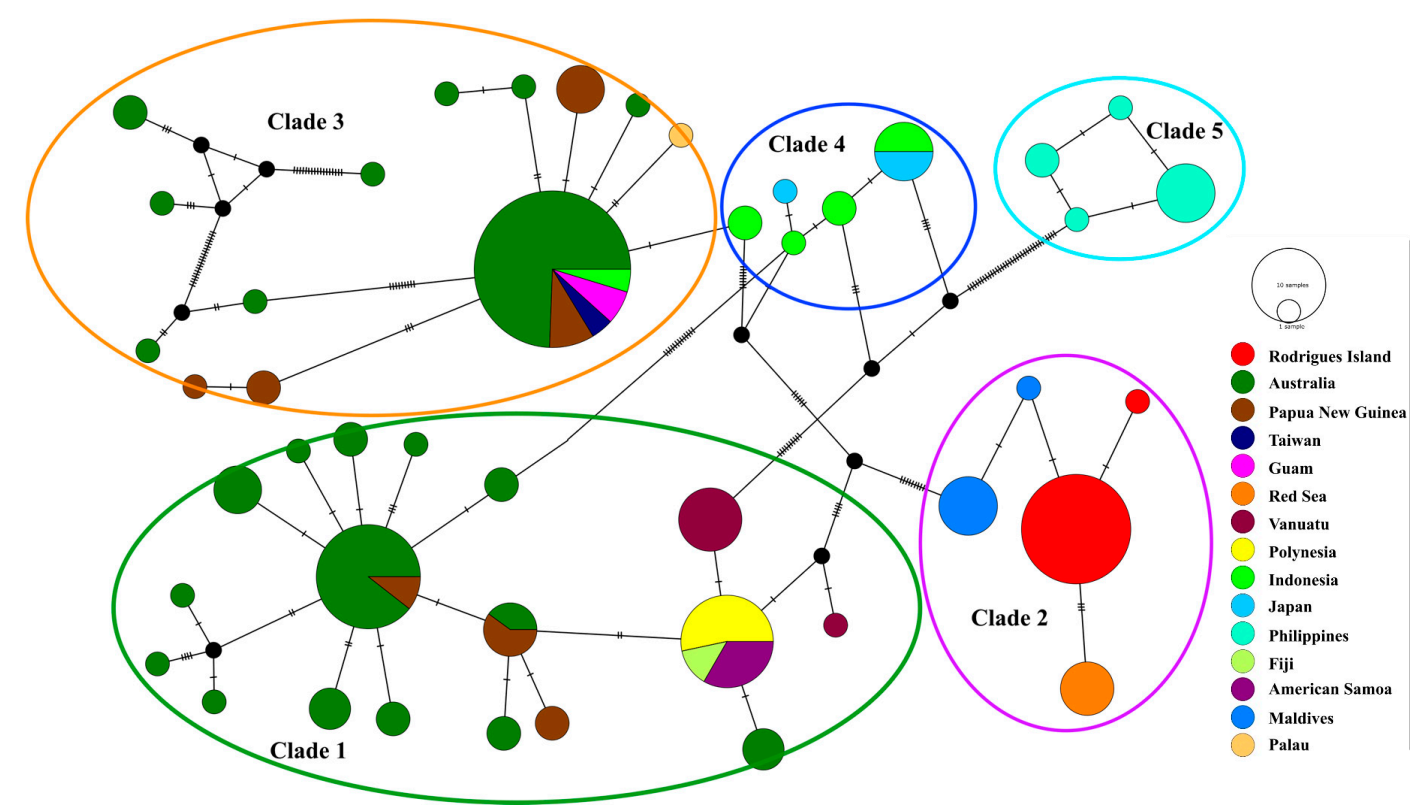

Figure 2. Haplotype network from cox3 sequences, with main clades circles indicating the lineages as in Figure 1. The size of the circles represents the sampling size. The hatch-marks represent mutational steps between haplotypes. Missing haplotypes are indicated by small black circles.

In general, few haplotypes are shared across the sampled biogeographic regions (Supplemental S7; Figure 1). However, Clade 1 (Figure 1) contained individuals from Polynesia, Fiji, and American Samoa, sharing the same cox3 haplotypes (Supplemental S7). Haplotypes from Clade 2, grouping regions from the IO, were distinct from the other clades, with no haplotypes shared even between sampling localities (Rodrigues, Maldives, and the Red Sea). The Maldives shared one 28S haplotype with Polynesia (Supplemental S7). Clade 3 shared one 285 haplotype for specimens obtained from Guam, Taiwan and Palau, whereas only Guam and Taiwan shared a cox3 haplotype. Clade 4 (Japan and Indonesia) shared one cox3 haplotype. Specimens from Clade 5, which was the most distinct one obtained from the phylogenetic tree (Figure 1) and the cox3 haplotype network (Figure 2), shared one haplotype with Australia and Indonesia with regards to the $28 \mathrm{~S}$ marker (Supplemental S7).

The AMOVA supports the hypothesis of high levels of genetic structure with $F s t=0.88(p<0.001)$ for the cox3 marker compared to the $28 S$ marker with Fst $=0.46(p<0.001)$ for $28 S$ (Table 2). Moreover, a high percentage variation (87.54) was observed for the cox3 marker among the different clades observed with a low percentage variation (12.46) within the clades. For the $28 \mathrm{~S}$ marker a lower percentage variation (46.23) was observed among populations compared to within populations (53.77). Further analyses based 
on pairwise comparisons ( $F s t$ ) showed significant differences ranging from 0.689 to 0.974 with the cox3 marker between the five clades obtained in Figures 1 and 2 (Supplemental S8).

Table 2. AMOVA results for among populations (Clades 1 to 5) and within populations. D.f.: degrees of freedom, s.s.: sum of squares, v.c.: variance components, \% var: \% of variation, and Fst: fixation index.

\begin{tabular}{|c|c|c|c|c|c|}
\hline \multicolumn{6}{|c|}{ AMOVA Results for $\operatorname{cox} 3$} \\
\hline Source of variation & d.f. & s.s. & v.c. & $\%$ var & Fst \\
\hline Among populations & 4 & 1456.36 & 10.92 & 87.54 & 0.88 \\
\hline Within populations & 183 & 284.456 & 1.55 & 12.46 & \\
\hline \multicolumn{6}{|c|}{ AMOVA Results for $28 S$} \\
\hline Source of variation & d.f. & s.s. & v.c. & $\%$ var & Fst \\
\hline Among populations & 4 & 85.08 & 0.62 & 46.23 & \\
\hline Within populations & 183 & 131.76 & 0.72 & 53.77 & 0.46 \\
\hline
\end{tabular}

Nucleotide diversity for both markers was low and ranged from 0.000 to 0.046 . Haplotype diversity ranged from 0.000 to 0.914 (Table 3). The global haplotype diversity was high for both cox3 (0.914) and $28 S$ (0.881) markers.

Table 3. Genetic diversity measure of each clade.

\begin{tabular}{cccccccccc}
\hline \multirow{2}{*}{ Grouping } & \multirow{2}{*}{ \# seq } & \multicolumn{3}{c}{ \# Haplotypes } & \multicolumn{2}{c}{ \# Variable Sites } & \multicolumn{2}{c}{ Nucleotide Diversity } & \multicolumn{2}{c}{ Haplotype Diversity } \\
\cline { 3 - 9 } & & cox3 & 28S & cox3 & 28S & cox3 & 28S & cox3 & 28S \\
\hline Global & 188 & 45 & 36 & 102 & 26 & 0.046 & 0.006 & 0.914 & 0.881 \\
Clade 1 & 72 & 19 & 25 & 30 & 23 & 0.008 & 0.006 & 0.875 & 0.856 \\
Clade 2 & 34 & 5 & 3 & 8 & 2 & 0.005 & 0.001 & 0.581 & 0.533 \\
Clade 3 & 62 & 14 & 8 & 54 & 9 & 0.012 & 0.001 & 0.517 & 0.344 \\
Clade 4 & 10 & 4 & 2 & 3 & 1 & 0.002 & 0.001 & 0.644 & 0.533 \\
Clade 5 & 10 & 4 & 1 & 2 & 0 & 0.002 & 0.000 & 0.644 & 0.000 \\
\hline
\end{tabular}

\section{Discussion}

Our findings confirm previous investigations that showed L. chagosensis as several genetically distinct but morphologically cryptic lineages [28,29]. To further disentangle the phylogenetic and phylogeographic relationships of L. chagosensis, we utilised for the first time two independent markers that previously were demonstrated to differ in their ability to resolve evolutionary histories of sponges [29,37], namely a nuclear and a mitochondrial gene. Combining a larger sample size in relation to previous studies and analysing a concatenated dataset merging both nuclear and mitochondrial sequences, here we provide a phylogenetic insight into what we could call the $L$. chagosensis species complex. Assuming that the pelagic larval dispersal (PLD) takes place for only few days $[48,49]$, the mixing of larvae across large geographical areas seems unlikely, thus contributing to the isolation of lineages, even in a relatively open system like the ocean. Our phylogenetic reconstruction (Figure 1) is consistent with the hypothesis that $L$. chagosensis is composed of morphologically cryptic lineages, with their distinct evolutionary histories presumably shaped by a combination of short PLD, geographic distance, and physical barriers, such as the rise of shelfs during the glacial period. In summary, Clades 1, 2, \& 5 were distinct to their respective geographic locations; namely the western PO, IO and the Philippines. Clades 3 and 4 showed some complexity in their phylogenetic relationships, as they grouped irrespective to the proximity of their sampling locations (it should be noted that the specimens of these two clades are predominately from the Coral Triangle).

\subsection{Deep Divergence and Biogeographical Overlap in Cryptic Lineages}

An important finding of our study is the newly discovered sister group relationship between the Indian Ocean specimens and the samples obtained from the central PO (Figure 1). This is not 
concordant with the various studies undertaken on marine species including reef invertebrates found in the IP region, where a distinct divergence among the IO and PO populations has been reported (reviewed in Crandall et al. [50]).

In order to unravel the complex array of L. chagosensis lineages, the five different clades (Figures 1 and 2) obtained across their biogeographic regions are discussed below.

\subsubsection{Western and Central PO (Clade 1)}

Clade 1 grouped samples from Australia, Papua New Guinea, Fiji, Polynesia, American Samoa, and Vanuatu, thus regrouping all samples from the Indo-Australian plate with high support values from ML and BI analyses (Figure 1). The relatively short distance between these regions may explain the groupings of those two regions in a single clade. In addition, the East Australian current and Equatorial Counter current potentially sustain the transfer of larvae and buds (asexual fragments), respectively, from the eastern part of Papua New Guinea to northern and eastern part of Australia, and from Papua New Guinea and East Australia to Fiji, Polynesia, American Samoa, and Vanuatu [28,29].

\subsubsection{Indian Ocean (Clade 2)}

In the phylogeny derived from the concatenated sequences, all samples from the IO formed a distinct clade, consistent with our hypothesis that no lineages are shared between the Indian and Pacific Oceans [29]. With the Australian and Eurasian plates colliding in the mid-Miocene, the water flow between the Pacific and the Indian Oceans was reduced [51]. The water level dropped drastically during the Pleistocene period, due to the glacial formation during that age, and the Sunda shelf was exposed [52]. This sea-level change created a barrier between the Indian and the Pacific Oceans, restricting gene flow that subsequently led to allopatric speciation in many cases [53]. For example, Gaither et al. [54] showed that the IP barrier at the glacial maxima and the ensuing lowered sea levels contributed towards shaping the evolutionary patterns of the reef fish Cephalopholis argus, showing two main haplogroups, one characterizing the IO and one characterizing the PO. The coral reef sea star Linckia laevigata also has limited gene flow between the $\mathrm{IO}$ and the PO, due to the sea fluctuations in the Pleistocene [23].

The L. chagosensis found in the IO is grouped together in Clade 2 (Figure 1), and a clear distinction of the different sampling locations was observed from the haplotype network (Figure 2, Supplemental S7). In contrast to other studies (e.g., Vogler et al. [22]), a deep genetic divergence between the Southern $\mathrm{IO}$, the Northern IO, and the Red Sea could not be observed. Nonetheless, no cox3 or $28 \mathrm{~S}$ haplotypes are shared between these regions (Figure 2, Supplemental S7). Therefore, gene flow between these regions in the western IO appears to be restricted for L. chagosensis. The Red Sea is separated from the remaining western IO by physical barriers, most notably by the shallow and narrow Strait of Bab al Mandab [55], and numerous phylogeographic studies have provided evidence for the deep genetic divergence of Red Sea marine species (e.g., DiBattista et al. [10,56]; Fernandez-Silva et al. [57]). Consistent with this hypothesis, we observed that $L$. chagosensis individuals sampled in Rodrigues are more closely related to those from the Red Sea than the geographically closer Maldives. The seasonal mixing of surface waters of the Red Sea and the western IO [58], which favours the transfer of larvae or asexual fragments between the Red Sea and Rodrigues, might also contribute to the observed phylogeographic pattern.

\subsubsection{Western PO (Clades 3, 4, and 5)}

Clade 3 is comprised of samples mainly from the northeast of Australia but also specimens from Papua New Guinea, Palau, Guam, and Taiwan (Figure 1). The North Equatorial Current likely promotes gene flow between these geographically relative proximate sites (Figure 1). The same scenario has been observed for the macroalga Sargassum aquifolium, where oceanic currents and land bridges have been reported to shape the S. aquifolium populations in the Southeast Asia region. A genetic break between populations was observed between Southeast Asia and the western Pacific Islands 
and Guam [59]. Furthermore, Clade 3 has diverged significantly with high support values from ML and BI analyses from Clade 1, which also contains samples from Australia and Papua New Guinea, clearly showing a distinction of two different lineages of L. chagosensis in the same biogeographic region, in concordance with previous results [29].

Clade 4 contains other samples from Japan and Indonesia. Considering the role of the North Equatorial current in mixing the surface waters from Indonesia and Japan (Figure 1), a phylogeographic relatedness would be expected between the samples collected in the western PO, as it is highlighted in Clade 3 . However, even though Clades 3 and 4 are phylogenetically more closely related to each other than to other clades, there is a clear separation between them (Figure 1). With the numerous island formations in that region and the sea level minima and maxima during glacial cycles, the complexity of speciation occurring on the different islands in that region is likely intensified [60]. Such phylogeographic complexity has also been reported for other species found in the western PO - for example, the mangrove species Excoecaria agallocha [61], the abalone Haliostis diversicolor [1], and the Neon damselfish Pomacentrus coelestis [62].

Clade 5 contains only samples from the Philippines, defining this geographic region as biogeographically distinct. Wörheide et al. [29] suggested a long isolation of L. chagosensis populations in the Philippines as a possible reason for its genetic divergence. The phylogeographic complexity of the Philippines archipelago has also been described in the case of the marine red alga Portiera [63], for which DNA taxonomy suggested that it is composed of 21 species within the Philippines, although it was previously assumed to be one widely distributed IP species based on morphology. Our study now reinforces the exceptional biogeographical role of the Philippine Archipelago by confirming the deep separation of L. chagosensis from the rest of the IP [29], based on the analysis of a mitochondrial locus.

\subsection{Genetic Structure and Diversity of L. chagosensis Across Its Range}

With the inclusion of a mitochondrial marker and the incorporation of additional samples from the IO, our study provides a unique opportunity to assess the genetic structure and diversity of the allegedly wide-ranging species L. chagosensis. The haplotype network based on the cox3 marker (Figure 2) retrieves five lineages, showing high levels of genetic structure, evidenced by the relatively large number of mutational steps between most lineages. High Fst values obtained from the cox3 marker (Table 2) also support the observation of highly structured populations. Most of the clades showed a high haplotype diversity and a low nucleotide diversity, which may indicate geographic population expansions within each clade [64]. Clade 5 (Philippines) has no values for the nucleotide and haplotype diversities, because the $28 S$ sequences were identical in this clade. The lack of genetic diversity may either be caused by a severe bottleneck effect of the Philippine population or be artefactual, due to the low number of samples obtained from that region. Clade 4 (Australia, Papua New Guinea, Guam, Palau, Taiwan, and Indonesia) was the only clade showing high nucleotide diversity with regards to cox3. This region comprises the Great Barrier Reef and also the part of the Coral Triangle, the latter of which is famous as a marine biodiversity hotspot for many marine taxa [65,66]. It also has been proposed to be a centre of overlap between the IO and PO [67], a centre of origin [68], and the centre of survival $[69,70]$.

\section{Conclusions}

In this study, we unravelled the phylogeographic relationships of L. chagosensis lineages across the known biogeographic range, using a combination of nuclear and mitochondrial DNA markers. The morphological taxonomy of L. chagosensis reveals only one species from the Indian to the Pacific Oceans. The results obtained from the molecular analyses suggest several genetic lineages isolated to their respective geographic location, with a relationship observed between the IO and the eastern PO. The isolation of the Philippines clade reiterates an urgent call for more L. chagosensis samples in that region, in order to understand its biogeographical importance. This demonstrates the benefits of applying the combined use of nuclear and mitochondrial markers for resolving sponge phylogeography. By including specimens from additional sites of the Indian Ocean, we provided further evidence that 
the L. chagosensis found in the central Indian Ocean are isolated from the Pacific Ocean, thus reinforcing the call for further phylogeographic studies in this biodiversity hotspot region, including for additional marine invertebrates. Such studies will specifically help to better understand the evolutionary patterns of connectivity of the Indian Ocean fauna to other parts of the Indo-Pacific region.

Supplementary Materials: The following are available online at http://www.mdpi.com/1424-2818/12/12/466/s1.

Author Contributions: Conceptualisation, analysis and original draft preparation: O.P. Supervision: S.v.d.H. Writing and editing: O.V., G.W., A.P.M.R. and S.v.d.H. All authors have read and agreed to the published version of the manuscript.

Funding: This project was funded by the Rufford Foundation and through a WIOMSA MARG I grant; O.P. was supported by a STIAS Doctoral Fellowship.

Acknowledgments: We wish to thank the Rodrigues Regional Assembly and the Prime Minister's Office in Mauritius for granting the permission for sampling in Rodrigues. A special thanks to Jerome Joseph and Reshad Jangheer Khan for helping in the collection of samples in Rodrigues. We wish to acknowledge Miriam Küstner for helping with the data generation, and also Nicole de Voogd for the sponge identification of specimens from Rodrigues Island, as well as for providing additional samples of L. chagosensis. G.W. acknowledges funding through the Ludwig-Maximilians-Universität Munich (LMU) Munich's Institutional Strategy LMUexcellent within the framework of the German Excellence Initiative.

Conflicts of Interest: The authors declare no conflict of interest.

\section{References}

1. Hsu, T.-H.; Gwo, J.-C. Genetic diversity and stock identification of small abalone (Haliotis diversicolor) in Taiwan and Japan. PLoS ONE 2017, 12, e0179818. [CrossRef]

2. Sun, Y.; Wong, E.; Ahyong, S.T.; Williamson, J.; Hutchings, P.; Kupriyanova, E.K. Barcoding and multi-locus phylogeography of the globally distributed calcareous tubeworm genus Hydroides Gunnerus, 1768 (Annelida, Polychaeta, Serpulidae). Mol. Phylogenet. Evol. 2018, 127, 732-745. [CrossRef]

3. Mouillot, D.; Parravicini, V.; Bellwood, D.R.; Leprieur, F.; Huang, D.; Cowman, P.F.; Albouy, C.; Hughes, T.P.; Thuiller, W.; Guilhaumon, F. Global marine protected areas do not secure the evolutionary history of tropical corals and fishes. Nat. Commun. 2016, 7, 10359. [CrossRef] [PubMed]

4. Huveneers, C.; Maes, G.E.; Green, M.E.; Simpfendorfer, C.A.; Hoyos-Padilla, E.M.; Duffy, C.J.A.; Meyer, C.G.; Kerwath, S.E.; Salinas-De-León, P.; Van Herwerden, L. Strong trans-Pacific break and local conservation units in the Galapagos shark (Carcharhinus galapagensis) revealed by genome-wide cytonuclear markers. Heredity 2018, 120, 407-421. [CrossRef]

5. von der Heyden, S. Making evolutionary history count: Biodiversity planning for coral reef fishes and the conservation of evolutionary processes. Coral Reefs 2016, 36, 183-194. [CrossRef]

6. Doney, S.C.; Ruckelshaus, M.; Duffy, J.E.; Barry, J.P.; Chan, F.; English, C.A.; Galindo, H.M.; Grebmeier, J.M.; Hollowed, A.B.; Knowlton, N.; et al. Climate Change Impacts on Marine Ecosystems. Annu. Rev. Mar. Sci. 2012, 4, 11-37. [CrossRef]

7. McClanahan, T.R.; Muthiga, N.A. Similar impacts of fishing and environmental stress on calcifying organisms in Indian Ocean coral reefs. Mar. Ecol. Prog. Ser. 2016, 560, 87-103. [CrossRef]

8. Fricke, R. Fishes of the Mascarene Islands (Reunion, Mauritius, Rodriguez). In An Annotated Checklist with Descriptions of New Species; Koeltz: Koenigstein, Germany, 1999.

9. Roberts, C.M.; McClean, C.J.; Veron, J.E.N.; Hawkins, J.P.; Allen, G.R.; McAllister, D.E.; Mittermeier, C.G.; Schueler, F.W.; Spalding, M.; Wells, F.; et al. Marine Biodiversity Hotspots and Conservation Priorities for Tropical Reefs. Science 2002, 295, 1280-1284. [CrossRef] [PubMed]

10. DiBattista, J.D.; Choat, J.H.; Gaither, M.R.; Hobbs, J.-P.A.; Lozano-Cortés, D.F.; Myers, R.F.; Paulay, G.; Rocha, L.A.; Toonen, R.J.; Westneat, M.W.; et al. On the origin of endemic species in the Red Sea. J. Biogeogr. 2015, 43, 13-30. [CrossRef]

11. Wilson, N.G.; Kirkendale, L.A. Putting the 'Indo' back into the Indo-Pacific: Resolving marine phylogeographic gaps. Invertebr. Syst. 2016, 30, 86-94. [CrossRef]

12. Chambers, D.P.; Tapley, B.D.; Stewart, R.H. Anomalous warming in the Indian Ocean coincident with El Niño. J. Geophys. Res. Space Phys. 1999, 104, 3035-3047. [CrossRef] 
13. Rao, S.A.; Dhakate, A.R.; Saha, S.K.; Mahapatra, S.; Chaudhari, H.S.; Pokhrel, S.; Sahu, S.K. Why is Indian Ocean warming consistently? Clim. Chang. 2012, 110, 709-719. [CrossRef]

14. Rydbeck, A.V.; Jensen, T.G.; Nyadjro, E.S. Intraseasonal sea surface warming in the western Indian Ocean by oceanic equatorial Rossby waves. Geophys. Res. Lett. 2017, 44, 4224-4232. [CrossRef]

15. Zhang, Y.; Feng, M.; Du, Y.; Phillips, H.E.; Bindoff, N.L.; McPhaden, M.J. Strengthened Indonesian Throughflow Drives Decadal Warming in the Southern Indian Ocean. Geophys. Res. Lett. 2018, 45, 6167-6175. [CrossRef]

16. van der Elst, R.; Everett, B.; Jiddawi, N.; Mwatha, G.; Afonso, P.S.; Boulle, D. Fish, fishers and fisheries of the Western Indian Ocean: Their diversity and status. A preliminary assessment. Philos. Trans. R. Soc. A Math. Phys. Eng. Sci. 2005, 363, 263-284. [CrossRef]

17. Fonteneau, A.; Lucas, V.; Tewkai, E.; Delgado, A.; Demarcq, H. Mesoscale exploitation of a major tuna concentration in the Indian Ocean. Aquat. Living Resour. 2008, 21, 109-121. [CrossRef]

18. Sharma, R.; Pons, M.; Martin, S.; Kell, L.; Walter, J.; Lauretta, M.; Schirripa, M. Factors related to the decline and rebuilding of billfish stocks in the Atlantic and Indian oceans. ICES J. Mar. Sci. 2017, 75, 880-891. [CrossRef]

19. Ahti, P.A.; Coleman, R.R.; DiBattista, J.D.; Berumen, M.L.; Rocha, L.A.; Bowen, B.W. Phylogeography of Indo-Pacific reef fishes: Sister wrasses Coris gaimard and C. cuvieri in the Red Sea, Indian Ocean and Pacific Ocean. J. Biogeogr. 2016, 43, 1103-1115. [CrossRef]

20. Borsa, P.; Durand, J.-D.; Chen, W.-J.; Hubert, N.; Muths, D.; Mou-Tham, G.; Kulbicki, M. Comparative phylogeography of the western Indian Ocean reef fauna. Acta Oecologica 2016, 72, 72-86. [CrossRef]

21. Benzie, J.A.H. Major genetic differences between crown-of-thorns starfish (Acanthaster planci) populations in the Indian and Pacific oceans. Evolution 1999, 53, 1782-1795. [CrossRef]

22. Vogler, C.; Benzie, J.; Lessios, H.; Barber, P.; Wörheide, G. A threat to coral reefs multiplied? Four species of crown-of-thorns starfish. Biol. Lett. 2008, 4, 696-699. [CrossRef] [PubMed]

23. Otwoma, L.M.; Kochzius, M. Genetic Population Structure of the Coral Reef Sea Star Linckia laevigata in the Western Indian Ocean and Indo-West Pacific. PLoS ONE 2016, 11, e0165552. [CrossRef] [PubMed]

24. Barnes, D.K.A.; Bell, J.J. Coastal sponge communities of the West Indian Ocean: Taxonomic affinities, richness and diversity. Afr. J. Ecol. 2002, 40, 337-349. [CrossRef]

25. van Soest, R.; De Voogd, N.J. Calcareous sponges of the Western Indian Ocean and Red Sea. Zootaxa 2018, 4426, 1-160. [CrossRef] [PubMed]

26. Dendy, A. No. I.-The Percy Sladen Trust Expedition to the Indian Ocean in 1905, under the Leadership of Mr. J. Stanley Gardiner, M.A. Volume V. No. I.-Report on the Calcareous Sponges collected by H.M.S. "Sealark" in the Indian Ocean. Trans. Linn. Soc. Lond. 1913, 16, 1-29. [CrossRef]

27. Trentin, F.; Massé, L. Première Approche de la Biodiversité des éponges à la Réunion. 2018. Available online: https://www.researchgate.net/publication/327039827_Premiere_approche_de_la_diversite_des_eponges_a _La_Reunion_Bilan_pour_la_DEAL_Reunion (accessed on 7 December 2020).

28. Wörheide, G.; Hooper, J.N.A.; Degnan, B.M. Phylogeography of western Pacific Leucetta 'chagosensis' (Porifera: Calcarea) from ribosomal DNA sequences: Implications for population history and conservation of the Great Barrier Reef World Heritage Area (Australia). Mol. Ecol. 2002, 11, 1753-1768. [CrossRef] [PubMed]

29. Wöerheide, G.; Epp, L.S.; Macis, L. Deep genetic divergences among Indo-Pacific populations of the coral reef sponge Leucetta chagosensis (Leucettidae): Founder effects, vicariance, or both? BMC Evol. Biol. 2008, 8, 24. [CrossRef]

30. Borojevic, R.; Boury-Esnault, N.; Vacelet, J. A revision of the supraspecific classification of the subclass Calcaronea (Porifera, class Calcarea). Zoosystema 2000, 22, 203-263.

31. Vogler, C.; Benzie, J.A.H.; Barber, P.H.; Erdmann, M.V.; Ambariyanto; Sheppard, C.; Tenggardjaja, K.; Gérard, K.; Wörheide, G. Phylogeography of the Crown-of-Thorns Starfish in the Indian Ocean. PLoS ONE 2012, 7, e43499. [CrossRef]

32. Lavrov, D.V.; Pett, W.; Voigt, O.; Wörheide, G.; Forget, L.; Lang, B.F.; Kayal, E. Mitochondrial DNA of Clathrina clathrus (Calcarea, Calcinea): Six Linear Chromosomes, Fragmented rRNAs, tRNA Editing, and a Novel Genetic Code. Mol. Biol. Evol. 2012, 30, 865-880. [CrossRef]

33. Becking, L.E.; Erpenbeck, D.; Peijnenburg, K.T.C.A.; de Voogd, N.J. Phylogeography of the Sponge Suberites diversicolor in Indonesia: Insights into the Evolution of Marine Lake Populations. PLoS ONE 2013, 8, e75996. [CrossRef] [PubMed] 
34. DeBiasse, M.B.; Richards, V.P.; Shivji, M.; Hellberg, M.E. Shared phylogeographical breaks in a Caribbean coral reef sponge and its invertebrate commensals. J. Biogeogr. 2016, 43, 2136-2146. [CrossRef]

35. Swierts, T.; Peijnenburg, K.T.C.A.; De Leeuw, C.A.; Breeuwer, J.A.J.; Cleary, D.F.R.; de Voogd, N.J. Globally intertwined evolutionary history of giant barrel sponges. Coral Reefs 2017, 36, 933-945. [CrossRef]

36. Wörheide, G.; Solé-Cava, A.M.; Hooper, J.N.A. Biodiversity, molecular ecology and phylogeography of marine sponges: Patterns, implications and outlooks. Integr. Comp. Biol. 2005, 45, 377-385. [CrossRef] [PubMed]

37. Voigt, O.; Eichmann, V.; Wöerheide, G. First evaluation of mitochondrial DNA as a marker for phylogeographic studies of Calcarea: A case study from Leucetta chagosensis. Hydrobiologia 2011, 687, 101-106. [CrossRef]

38. Kearse, M.; Moir, R.; Wilson, A.; Stones-Havas, S.; Cheung, M.; Sturrock, S.; Buxton, S.; Cooper, A.; Markowitz, S.; Duran, C.; et al. Geneious Basic: An integrated and extendable desktop software platform for the organization and analysis of sequence data. Bioinformatics 2012, 28, 1647-1649. [CrossRef]

39. Edgar, R.C. MUSCLE: Multiple sequence alignment with high accuracy and high throughput. Nucleic Acids Res. 2004, 32, 1792-1797. [CrossRef]

40. Chernomor, O.; von Haeseler, A.; Minh, B.Q. Terrace Aware Data Structure for Phylogenomic Inference from Supermatrices. Syst. Biol. 2016, 65, 997-1008. [CrossRef]

41. Kalyaanamoorthy, S.; Minh, B.Q.; Wong, T.K.F.; Von Haeseler, A.; Jermiin, L.S. ModelFinder: Fast model selection for accurate phylogenetic estimates. Nat. Methods 2017, 14, 587-589. [CrossRef]

42. Hoang, D.T.; Chernomor, O.; von Haeseler, A.; Minh, B.Q.; Vinh, L.S. UFBoot2: Improving the ultrafast bootstrap approximation. Mol. Biol. Evol. 2018, 35, 518-522. [CrossRef]

43. Huelsenbeck, J.P.; Ronquist, F. MRBAYES: Bayesian inference of phylogeny. Bioinformatics 2001, 17, 754-755. [CrossRef] [PubMed]

44. Ronquist, F.; Huelsenbeck, J.P. MrBayes 3: Bayesian phylogenetic inference under mixed models. Bioinformatics 2003, 19, 1572-1574. [CrossRef] [PubMed]

45. Clement, M.J.; Snell, Q.; Walker, P.; Posada, D.; Crandall, K.A. TCS: Estimating gene genealogies. In Proceedings of the 16th International Parallel and Distributed Processing Symposium, Lauderdale, FL, USA, 15-19 April 2002.

46. Rozas, J.; Ferrer-Mata, A.; Sánchez-DelBarrio, J.C.; Guirao-Rico, S.; Librado, P.; Ramos-Onsins, S.E.; Sánchez-Gracia, A. DnaSP 6: DNA Sequence Polymorphism Analysis of Large Data Sets. Mol. Biol. Evol. 2017, 34, 3299-3302. [CrossRef] [PubMed]

47. Excoffier, L.; Lischer, H.E.L. Arlequin suite ver 3.5: A new series of programs to perform population genetics analyses under Linux and Windows. Mol. Ecol. Resour. 2010, 10, 564-567. [CrossRef] [PubMed]

48. Maldonado, M.; Young, C. Effects of physical factors on larval behavior, settlement and recruitment of four tropical demosponges. Mar. Ecol. Prog. Ser. 1996, 138, 169-180. [CrossRef]

49. Uriz, M.J.; Maldonado, M.; Turon, X.; Martí, R. How do reproductive output, larval behaviour, and recruitment contribute to adult spatial patterns in Mediterranean encrusting sponges? Mar. Ecol. Prog. Ser. 1998, 167, 137-148. [CrossRef]

50. Crandall, E.D.; Riginos, C.; Bird, C.E.; Liggins, L.; Treml, E.A.; Beger, M.; Barber, P.H.; Connolly, S.R.; Cowman, P.F.; DiBattista, J.D.; et al. The molecular biogeography of the Indo-Pacific: Testing hypotheses with multispecies genetic patterns. Glob. Ecol. Biogeogr. 2019, 28, 943-960. [CrossRef]

51. Kennett, J.P.; Keller, G.; Srinivasan, M.S. Miocene planktonic foraminiferal biogeography and paleoceanographic development of the Indo-Pacific region. Geol. Soc. Am. Mem. 1985, 163, 197-236. [CrossRef]

52. Voris, H.K. Maps of Pleistocene sea levels in Southeast Asia: Shorelines, river systems and time durations. J. Biogeogr. 2000, 27, 1153-1167. [CrossRef]

53. Bowen, B.W.; Gaither, M.R.; DiBattista, J.D.; Iacchei, M.; Andrews, K.R.; Grant, W.S.; Toonen, R.J.; Briggs, J.C. Comparative phylogeography of the ocean planet. Proc. Natl. Acad. Sci. USA 2016, 113, 7962-7969. [CrossRef]

54. Gaither, M.R.; Bowen, B.W.; Bordenave, T.-R.; Rocha, L.A.; Newman, S.J.; Gomez, J.A.; van Herwerden, L.; Craig, M.T. Phylogeography of the reef fish Cephalopholis argus (Epinephelidae) indicates Pleistocene isolation across the Indo-Pacific barrier with contemporary overlap in the coral triangle. BMC Evol. Biol. 2011, 11, 189. [CrossRef] [PubMed]

55. Siddall, M.E.; Rohling, E.J.; Almogilabin, A.; Hemleben, C.; Meischner, D.; Schmelzer, I.; Smeed, D.A. Sea-level fluctuations during the last glacial cycle. Nat. Cell Biol. 2003, 423, 853-858. [CrossRef] [PubMed] 
56. DiBattista, J.D.; Berumen, M.L.; Gaither, M.R.; Rocha, L.A.; Eble, J.A.; Choat, J.H.; Craig, M.T.; Skillings, D.J.; Bowen, B.W. After continents divide: Comparative phylogeography of reef fishes from the Red Sea and Indian Ocean. J. Biogeogr. 2013, 40, 1170-1181. [CrossRef]

57. Fernandez-Silva, I.; Randall, J.E.; Coleman, R.R.; DiBattista, J.D.; Rocha, L.A.; Reimer, J.D.; Meyer, C.G.; Bowen, B.W. Yellow tails in the Red Sea: Phylogeography of the Indo-Pacific goatfish Mulloidichthys flavolineatus reveals isolation in peripheral provinces and cryptic evolutionary lineages. J. Biogeogr. 2015, 42, 2402-2413. [CrossRef]

58. Obura, D. The Diversity and Biogeography of Western Indian Ocean Reef-Building Corals. PLoS ONE 2012, 7, e45013. [CrossRef] [PubMed]

59. Chan, S.W.; Cheang, C.C.; Yeung, C.W.; Chirapart, A.; Gerung, G.; Ang, P. Recent expansion led to the lack of genetic structure of Sargassum aquifolium populations in Southeast Asia. Mar. Biol. 2014, 161, 785-795. [CrossRef]

60. Woodruff, D.S. Biogeography and conservation in Southeast Asia: How 2.7 million years of repeated environmental fluctuations affect today's patterns and the future of the remaining refugial-phase biodiversity. Biodivers. Conserv. 2010, 19, 919-941. [CrossRef]

61. Guo, W.; Ng, W.L.; Wu, H.; Li, W.; Zhang, L.; Qiao, S.; Yang, X.; Shi, X.; Huang, Y.-L. Chloroplast phylogeography of a widely distributed mangrove species, Excoecaria agallocha, in the Indo-West Pacific region. Hydrobiologia 2017, 807, 333-347. [CrossRef]

62. Sorenson, L.; Allen, G.R.; Erdmann, M.V.; Dai, C.-F.; Liu, S.Y.V. Pleistocene diversification of the Pomacentrus coelestis species complex (Pisces: Pomacentridae): Historical biogeography and species boundaries. Mar. Biol. 2014, 161, 2495-2507. [CrossRef]

63. Payo, D.A.; Leliaert, F.; Verbruggen, H.; D’Hondt, S.; Calumpong, H.P.; De Clerck, O. Extensive cryptic species diversity and fine-scale endemism in the marine red alga Portieria in the Philippines. Proc. R. Soc. B Boil. Sci. 2013, 280, 20122660. [CrossRef]

64. Grant, W. Shallow population histories in deep evolutionary lineages of marine fishes: Insights from sardines and anchovies and lessons for conservation. J. Hered. 1998, 89, 415-426. [CrossRef]

65. Bellwood, D.R.; Renema, W.; Rosen, B.R. Biodiversity hotspots, evolution and coral reef biogeography: A review. In Biotic Evolution and Environmental Change in Southeast Asia: Systematics Association Special; Gower, D.J., Johnson, K.G., Richardson, J.E., Rosen, B.R., Rüber, L., Williams, S.T., Eds.; Cambridge University Press (CUP): Cambridge, UK, 2012; pp. 216-245.

66. Briggs, J.C.; Bowen, B.W. Marine shelf habitat: Biogeography and evolution. J. Biogeogr. 2013, 40, $1023-1035$. [CrossRef]

67. Gaither, M.R.; Rocha, L.A. Origins of species richness in the Indo-Malay-Philippine biodiversity hotspot: Evidence for the centre of overlap hypothesis. J. Biogeogr. 2013, 40, 1638-1648. [CrossRef]

68. Briggs, J.C. Centrifugal speciation and centres of origin. J. Biogeogr. 2000, 27, 1183-1188. [CrossRef]

69. Bellwood, D.; Meyer, C.P. Searching for heat in a marine biodiversity hotspot. J. Biogeogr. 2009, 36, 569-576. [CrossRef]

70. Evans, S.M.; McKenna, C.; Simpson, S.D.; Tournois, J.; Genner, M.J. Patterns of species range evolution in Indo-Pacific reef assemblages reveal the Coral Triangle as a net source of transoceanic diversity. Biol. Lett. 2016, 12, 20160090. [CrossRef]

Publisher's Note: MDPI stays neutral with regard to jurisdictional claims in published maps and institutional affiliations.

(C) 2020 by the authors. Licensee MDPI, Basel, Switzerland. This article is an open access article distributed under the terms and conditions of the Creative Commons Attribution (CC BY) license (http://creativecommons.org/licenses/by/4.0/). 